\begin{tabular}{|ccc}
\hline Sournals & $\begin{array}{c}\text { INTERNATIONAL JOURNAL OF } \\
\text { ORGANIZATIONAL LEADERSHIP }\end{array}$ & $\begin{array}{c}\text { INDUSTRIAL } \\
\text { MANAGEMENT } \\
\text { INSTITUTE }\end{array}$ \\
\hline \hline
\end{tabular}

\title{
Impact of Abusive Supervision on Turnover Intention Through Future Work Self-Salience and Organization- Based Self-Esteem
}

\author{
Muhammad Arif ${ }^{1}$, Muzammal Ilyas Sindhu ${ }^{2}$, Syeda Faiza Urooj ${ }^{3}$, Shujahat Haider \\ Hashmi $^{4^{*}}$ \\ ${ }^{1}$ Associate Professor, Bahria University, Islamabad Pakistan \\ ${ }^{2}$ Ph.D. Scholar, Bahria University, Islamabad Pakistan \\ ${ }^{3}$ Assistant Professor, Federal Urdu University, Islamabad Pakistan \\ ${ }^{4}$ Lecturer, Capital University of Science and Technology, Islamabad Pakistan
}

\section{Keywords: \\ Abusive Supervision, Turnover Intention, FWSS, OBSE, Regression \\ Analysis, Moderation and Mediation}

Received

12 October 2016

Received in revised form 28 November 2017

Accepted

05 December 2017

Correspondence:

shujahat_hashmi@hotmail.com

\section{Abstract}

The purpose of this study is to examine the impact of abusive supervision on turnover intention through future work self-salience and organization-based self-esteem. We further anticipated that OBSE would have a moderating influence on the association of AS and TOI.Data has been collected using questionnaire and servicing sector of Pakistan as the target population is considered important for this study. Research analysis indicated that FWSS had a partial intervening influence of the association between AS and TOI, whereas, OBSE had a moderating influence on the path of AS and TOI association. Although this study is going to identity the impact of abusive supervision on turnover intention through future work self-salience and organization-based self-esteem in Pakistani servicing sector but it lemmatizes the generalizability of studies at global level. This study contributes to identity the influence of Abusive behavior of supervisor on turnover intention through FWSS and OBSE. It was anticipated that FWSS which demonstrates the easiness of creation and precision of a person's hope for work-based ID. Furthermore, it will contribute to modify the policy implications for organizational development through supervisory behavior development.

CAIMI Journals enhances automatically. Effective management and supervision leads to upgrading the organizational culture which tends to make betterment in productivity, efficiency, efficacy, and 
performance of the employees. Abusive supervision is associated with diminishing in job performance (Harris, Kacmar, \& Zivnuska, 2007). Frost and Hoggett (2008)examined that misuse of authorities by supervisors worsen the leader member exchange relationship. The quality of this relationship is based on inter-personal communication and employees' physical and psychological well-being which leads to their personal and professional growth, job satisfaction, and performance. Organizations have to pay massive financial and non-financial costs of abusive supervision and it is an unavoidable threat to psychological and social wellbeing of the workforce. It has an adverse impact on their interpersonal relationships, communication, and overall performance which ultimately is a warning of future declining of that organization.

Earlier ID-based studies inside the organizations have supposed that ID-related effect on performance is common with respect to personnel (Johnson \& Lord, 2010). So, ID-Based perspective indicates that the ID based salience could deviate and shows a significant role across impacting personal behaviors of employees (Albert, Ashforth, \& Dutton, 2000). Moreover, it has been analyzed that employees' FWSS is important for the reputation of workbased ID and it may have moderating impact on the relationship between abusive supervision and turnover intention.

$\mathrm{Yu}$ et al. (2014) studied the intervening impact of affective commitment in between the association between abusive supervision and employee work efficiency with the intervening part of FWSS. They mentioned that this way of inquiry must illuminate ID magnitudes of abusive supervision on attitudinal outcomes. Vogel \& Mitchell (in press) in their research on the motivational effects of self-esteem for employees who experience abusive supervision recommended use of other intervening variables on the association of abusive supervision and attitudinal variables.

The resolution of this research is to discover the intervening impact of FWSS on the association between the abusive supervision and turnover intent of the operatives. Furthermore, to assess the middling impact of OBSE on the association between the abusive supervision (AS) and turnover intent are the main focus of the research study. The study will add an insight to the organizations about intermediary impact of future work self-salience (FWSS) and role played by OBSE as a moderator on the abusive supervision-turnover intent association. Moreover, the proposed study will add to enlightenment about the psychological and behavioral magnitudes of abusive supervision. This study wants to explore the exceptional function of FWSS in the abusive supervision-turnover intention association. These functions may be as a future-oriented and work-based identity.

\section{The Literature Review}

Description of dark aspect of leadership (Martinko, Harvey, Brees, \& Mackey, 2013), abusive supervision, has been under consideration for years. Abusive supervision and abusive behavior of supervisors which excludes their physical connection are unfriendly (Tepper, 2000) and seem parallel to tyrannical utilization of own power over subordinates. This abusive supervision damages one's capability to work efficiently. It is negatively associated with organizational commitment (Aryee, Chen, Sun, \& Debrah, 2007), job satisfaction (Lin, Wang, $\&$ Chen, 2013), and job performance (Aryee, Sun, Chen, \& Debrah, 2008). Following this, it is 
positively associated with emotional exhaustion and job turnover (Harvey, Stoner, Hochwarter, \& Kacmar, 2007) and aberrant behaviour (Thau, Bennett, Mitchell, \& Marrs, 2009). Abusive leaders' identity is positively associated with abusive supervision while abusive follower's identity is not participating in abusive supervision.

\section{Future Work Self-Salience}

Future work selves consisted of hope for self, expected self, and feared self (Markus \& Nurius, 1986). The concept of future work selves stems from construct called possible selves (Markus $\&$ Nurius, 1986). Work ID is significantly associated with work related self-conception. This self-conception consisted of an inter association of organizational, professional, and rest of the IDs. These IDs could be in form of Person-related-ID, Interpersonal-ID or collectivism-basedID and their salience can deviate (Turner \& Onorato, 1999). Albert et al. (2000) analyzed that the variations in IDs' salience is associated with different behaviour in identical social context.

\section{Organization-Based Self-Esteem}

OBSE designates feelings of any employee within their workplace (Payne, 2007). OBSE is those limits up to which an employee relies on statement that he can fulfill his necessities by working organization (Pierce, Gardner, Dunham, \& Cummings, 1993). It can also reveal employees' self-perception about their significance, efficacy, competency, and importance inside their organization (Chan, 2000). This organizational value and importance are grounded on antiquity of their managerial, personal, and universal practices (Pierce, Gardner, Cummings, \& Dunham, 1989). Better OBSE indicates that employees are momentous, efficacious, and worthy in organizations where they work (Pierceet al., 1989).

\section{Turnover Intention}

Bakhshi, Kumar, and Rani (2009) revealed that individual's feeling to leave organization is known as turnover intention. Cropanzano, Rupp and Byrne (2003) examined that turnover intention is the organizational events, psychological factors, and working conditions which develop an employee's attitude of staying or quitting the organization voluntarily. Turnover is costly affair of any organization (Nadiri \& Tanova, 2010) because it negatively influences other employees in some ways such as organization's morale, service provision, lower productivity, inefficient team work, LMX relationships, and financial implications.

\section{Abusive Supervision and Turnover Intention}

There is a strong association between abusive supervision and high levels of turnover tendencies (Tepper, 2000). Workers' job expectancies and supervisory relationships have storing associations because as these expectancies are met, they will lead to reducing the turnover intentions and vice versa.A large quantity of turnover models also proposed that elements which increase undesirable and damaging emotional assessments of one's job will indorse withdrawal (Griffeth, Hom \& Gaertner, 2000). 


\section{Organization-Based Self-Esteem and Turnover Intention}

Pierce and Gardner (2004) indicated that historical studies have explored negative relationships in the middle of employee OBSE and turnover intentions. In addition, it is stated that employees with high feelings of self-worth and self-importance who are ensured organizationally proficient in a way which secure them, prefer to work for that organization (Payne, 2007). Hui and Lee (2000) explored that worker possessing low levels of OBSE leads to lower organizational commitment and high levels of absenteeism. OBSE has been examined as moderating variable in various researches.

\section{The Study}

Figure 1 shows the theoretical framework of the study.

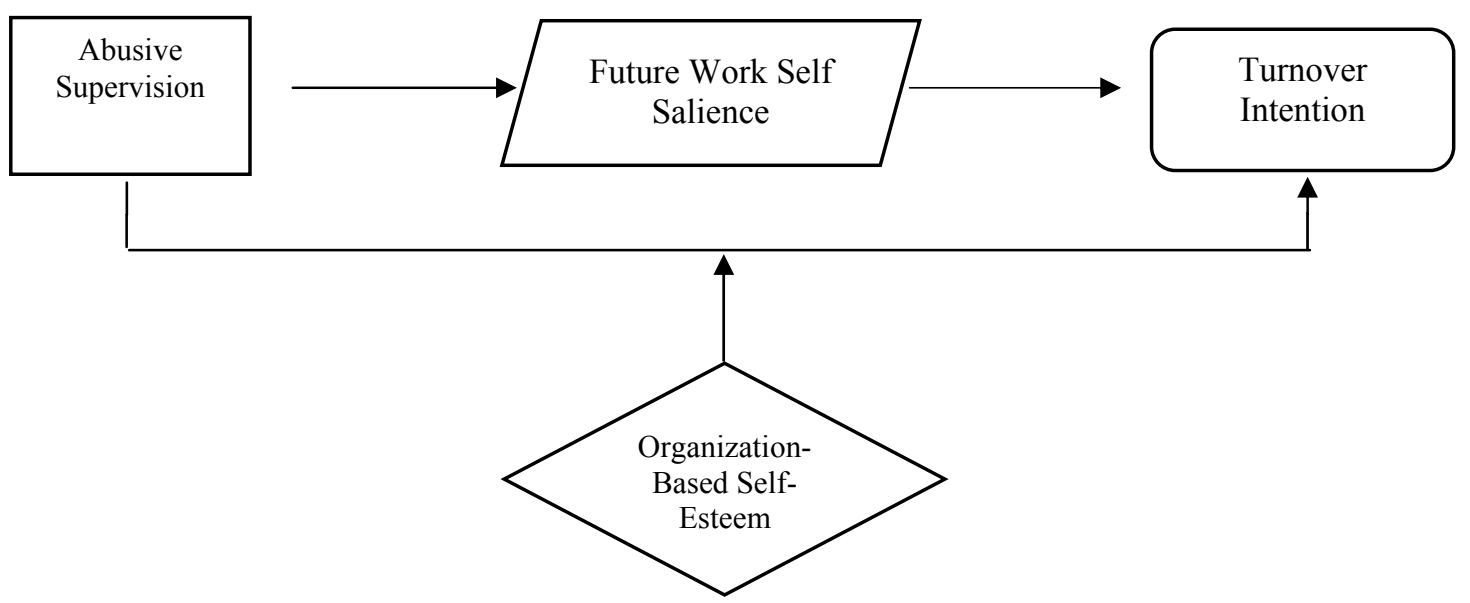

Figure1.Theoretical framework

\section{Research Hypotheses}

The following research hypotheses guided the study:

$\mathbf{H}_{1}$ : There is a positive association between abusive supervision and employees' turnover intention.

$\mathbf{H}_{2:}$ Abusive supervision negatively affects future work self-salience of the employees.

$\mathbf{H}_{3}$ : Future work self-salience of employees is positively related to employees' turnover intention.

$\mathbf{H}_{4}$ : FWSS mediates association between abusive supervision and turnover intention of employees.

$\mathbf{H}_{5}$ : Organization-based self-esteem moderates association between abusive supervision and turnover intention.

\section{Method}

The current study which is a causal, cross-sectional and quantitative study aimed to investigate the effect of abusive supervision on turnover intentions with the mediating role of future work self-salience and moderating role of employees' organization-based self-esteem. 
Convenient sampling approach is used for sample selection. Target population included the servicing employees working in the Telecom organizations of Rawalpindi and Islamabad.

The findings are based on a sample of 452 employees who were approached for data collection using questionnaires of five Likert scale. Measurement scales have been adopted from the following studies shown in Table 1.

Table 1

Measurement Scales

\begin{tabular}{lcl}
\hline Variable & No. of items & \multicolumn{1}{c}{ Authors } \\
\hline Abusive Supervision & 10 & Mitchell and Ambrose (2007) \\
Future Work Self Salience(FWSS) & 5 & King \& Patterson (2000) \\
Turnover Intent (TI) & 8 & Branden (1969) \\
Organization-Based Self Esteem (OBSE) & 11 & Uçar and Uzun (2008) \\
\hline
\end{tabular}

\section{Results}

The summary of the demographics has been described in Table 2. According to the demographics, majority of samples show that age group fall between 20-30 and these are nonmanagerial male respondents. They only hold a bachelor degree.

Table 2

Demographic Variables

\begin{tabular}{lccc}
\hline & Frequency & Percent & Cumulative\% \\
\hline Age & 302 & 66.8 & 66.8 \\
$20-30$ & 125 & 27.7 & 94.5 \\
$31-40$ & 19 & 4.2 & 98.7 \\
$41-50$ & 6 & 1.3 & 100 \\
Above 51 & & & 63.1 \\
\hline Gender & 285 & 63.1 & 100 \\
Male & 167 & 36.9 & 46.7 \\
Female & & 46.7 & 89.2 \\
\hline Qualification & 211 & 42.5 & 99.1 \\
Bachelors & 192 & 10 & 100 \\
Masters & 45 & 0.9 & 70.79 \\
MS & 4 & & 100 \\
PhD & & 70.79 & 29.21 \\
\hline Level of Job & 320 & 132 & \\
None manager & 45 & \\
Manager & & & \\
\hline
\end{tabular}

Cronbach alpha is the indication of the reliability of each variable. According to opinions of different analysts and researchers, we come to mutual consensus that reliability value should be in between 0.6 to 0.9 . The results of research study conferred appropriate adequacy level and values of Cronbach's Alpha of different variables ranged from 0.68 to 0.85 . Table 3 presents the reliability test. 
Table 3

Reliability Test

\begin{tabular}{lc}
\hline Variables & Cronbach Alpha \\
\hline Abusive Supervision & 0.79 \\
Future Work Self Salience (FWSS) & 0.68 \\
Turnover Intent (TI) & 0.85 \\
Organization-Based Self-Esteem (OBSE) & 0.81 \\
\hline
\end{tabular}

\section{Descriptive Statistics}

Descriptive statistics indicates mean, minimum, and maximum values. Mean values show that they are present on average and these values do not exceed from the limits of minimum and maximum. All the values of above four variables are in between 1 and 5 while the mean values are about middle. Table 4 exhibits the descriptive statistics.

Table 4

Descriptive Statistics

\begin{tabular}{lcccccr}
\hline & Minimum & Maximum & Mean & Std. Dev & Skewness & Kurtosis \\
\hline AS & 1.00 & 4.50 & 2.26 & 0.96 & 0.05 & -1.38 \\
FWSS & 1.00 & 4.60 & 2.87 & 0.95 & -0.48 & -0.52 \\
OBSE & 1.00 & 4.27 & 2.82 & 0.78 & -0.01 & 0.50 \\
TI & 1.00 & 4.38 & 2.88 & 0.85 & -0.94 & 0.29 \\
\hline
\end{tabular}

Skewness and kurtosis are measures of normality in which Skewness values should be near to zero ignoring the sign. Values of Skewness of all four variables are less than one which is indication of normal data. Kurtosis is another measure of normality in which value should not exceed three and here all the values are in between the limits. Kurtosis values are indication of the flatter distributions which demonstrated that data is normal.

\section{Correlation Matrix}

Correlation indicates relationship between the dependent, independent, and moderating variables. This study identifies the impact of abusive supervision on turnover intention through future work self-salience and organization-based self-esteem. Table 5 represents the correlation matrix.

Table 5

Correlation Matrix

\begin{tabular}{|c|c|c|c|c|}
\hline & AS & FWSS & OBSE & TI \\
\hline Abusive Supervision (AS) & 1.00 & & & \\
\hline Future Work Selfsalience (FWSS) & $0.44^{* *}$ & 1.00 & & \\
\hline Organization-Based Self-esteem (OBSE) & $0.45^{* *}$ & $0.76^{* *}$ & 1.00 & \\
\hline Turnover Intention (TI) & $0.38^{* *}$ & $0.84^{* *}$ & $0.83^{* *}$ & 1.00 \\
\hline
\end{tabular}

**Significant at 0.01 level 
The correlation coefficients showed that association between the variables is strongly significant. That is an indication of high degree of connection between two variables. Our correlations analysis revealed that all independent variables have significant correlation with dependent variable.

\section{Regression Analyses}

Regression analysis indicates the dependence of one variable upon other. Coefficients show the degree of dependence. Probability and t-values are indication of significance that show which independent variable contributes in variation of dependent variable.Here mediation and moderation test are also performed to testify the effects of independent upon dependents.Rsquare indicates the overall variation of variables while significant value of F-statistics shows the goodness and fitness of variables.

First model shows that abusive supervision significantly affects the turnover intention. It is simple regression analysis which presents that one unit change in abusive supervision will lead to 0.34 unit variation in turnover intention. This depicted that abusive behavior of supervisor will convince the subordinates to leave the organization and this is a reason on the behalf of abnormal behavior that will negatively affect the performance of organization. In addition, it is also noted that the abusive supervision significantly affects FWSS and FWSS affects turnover intention. It is an indication of mediation effect of FWSS in between abusive supervision and turnover intention. Table 6 illustrates the regression and mediation effect.

Table 6

Regression and Mediation Effect

\begin{tabular}{rlrrrrr}
\hline Model & Test & B & t-Value & Sig & R square & F-Stat \\
\hline $\mathbf{1}$ & AS $\rightarrow$ TI & 0.343 & 9.000 & 0.000 & 0.150 & 80 \\
\hline $\mathbf{2}$ & AS $\rightarrow$ FWSS & 1.882 & 10.540 & 0.000 & 0.200 & 111 \\
$\mathbf{3}$ & FWSS $\rightarrow$ TI & 0.752 & 29.660 & 0.000 & 0.710 & 558 \\
\hline
\end{tabular}

$N=452,(p<0.05)$

a. Dependent Variable: TI

b. Predictors: $A S=$ Abusive Supervision; FWSS $=$ Future Work Self Salience

\section{Moderating Role of OBSE}

Simple regression analysis indicates the dependence of predicting variables upon predictors while moderators are the intervening variables which affect the dependence of two variables. In this study organization-based self-esteem shows a moderating impact between abusive supervision and turnover intention. Here in first stage, OBSE significantly affects the turnover intention. Abusive supervision also contributes in turnover intention. Furthermore, it is also noticed that OBSE contributes in making variations in turnover intention as a moderator but its role is negative which means that organization-based self-esteem will lead to make adverse changes in turnover intention. Better OBSE will reduce the turnover intention. Table 7 clearly indicates the regression and moderation effect. 
Table 7

Regression and Moderation Effect

\begin{tabular}{rlrrrrr}
\hline Model & Test & B & t-value & Sign & R-square & F-Stat \\
\hline $\mathbf{1}$ & OBSE $\rightarrow$ TI & 0.787 & 19.14 & 0.000 & 0.734 & 1070 \\
$\mathbf{2}$ & AS $\rightarrow$ TI & 0.063 & 2.154 & 0.000 & 0.734 & 1070 \\
$\mathbf{3}$ & AS * OBSE $\rightarrow$ TI & -0.220 & -6.410 & 0.000 & 0.734 & 1070 \\
\hline
\end{tabular}

$N=452,(p<0.05)$

a. Dependent Variable: $T I$

b. Predictors: $A S=$ Abusive Supervision; OBSE= Organization-Based Self Esteem

\section{Discussion and Conclusion}

The results of this study approximately matched with the historical studies which highlighted the significance of the current study. Purpose of this study was to find out whether there exists any relationship between abusive supervision and turnover intentions. In addition, the study also sought to investigate that whether abusive supervision positively influences Future Work Self Salience (FWSS) of the employees. Further, it was assessed that FWSS of employees is positively associated with the turnover intention. The mediating influence of FWSS on the association of abusive supervision and turnover intention was tested and the moderating impact of organization-based self-esteem (OBSE) was also empirically tested.

This study is based on questionnaire which was delivered to servicing employees of telecom industry. Research analysis is examined through correlation and regression analysis. It is concluded that abusive supervision was directly proportional to production, time pressure, and work overload. Abusive supervision is positively influencing the turnover intention because this thing convinces the employees of organization to leave the organization or at least think about leaving the organization. It means that with increase in degree of abusive supervision, turnover intentions of the employees may rise. The present study's outcomes demonstrated that abusive supervision and turnover intention association is aligned with historical studies (Mitchel \& Ambrose, 2007). Moreover, employees' jobs and work related stress are inclined to enhance upon perceiving abusive supervision and as a result they lead the way to their intentions to quit that organization (Haris, Kacmar, \& Zivnuska 2007).

Abusive supervision or harsh supervision positively impacts the employees with future work self-salience (FWSS) that is more probable to turn their actions correspondingly and thus, these are tending towards low levels of patience when it comes to unfavorable aspects of organization. FWSS of employees is positively associated with turnover intention of the employees. The reduction in employee's perception regarding professional affiliation and work related ID's will lead to increase in the proportion of turnover intent.

The analyses and findings carried out in this study regarding the moderating influence of OBSE (Organization-Based Self-esteem) onto the association of Abusive Supervision and Turnover Intention. The subordinates and workers of such an ilk utilize querying upward dissension approach to raise queries against the management practices, service rules and bylaws, and organizational strategies and policies. In this context, OBSE will enhance the abusive supervision and turnover intention. 
Taken as a whole, the results of the present study accentuate the significance of enhancing the feelings of organization-based self-respect and organization-based self-confidence (the two facets of organization-based self-esteem) of the workers and operatives to bring down the high graph of intentions to leave. Furthermore, examination of the interaction showed that OBSE significantly and negatively affect the TI. The proposed model in this study was consistent with the hypothesis that OBSE negatively moderates the relationship between AS and TI.

\section{References}

Albert, S., Ashforth, B. E., \& Dutton, J. E. (2000). Organizational identity and identification: Charting new waters and building new bridges. Academy of Management Review, 25(1), 13-17.

Aryee, S., Chen, Z. X., Sun, L. Y., \& Debrah, Y. A. (2007). Antecedents and outcomes of abusive supervision: Test of a trickle-down model. Journal of Applied Psychology, 92(1), 191-201.

Aryee, S., Sun, L. Y., Chen, Z. X. G., \& Debrah, Y. A. (2008). Abusive supervision and contextual performance: The mediating role of emotional exhaustion and the moderating role of work unit structure. Management \& Organization Review, 4(3), 393-411.

Bakhshi, A., Kumar, K., \& Rani, E. (2009). Organizational justice perceptions as predictor of job satisfaction and organization commitment. International Journal of Business \& Management, 4(9), 145-154.

Branden, N. (1969). Free will, moral responsibilityand thelaw. Southern California Law Review, 42, $264-91$.

Chan, Y. M. (2000). Self-esteem: A cross-cultural comparison of British-Chinese, white British and Hong Kong Chinese children. Educational Psychology, 20(1), 59-74.

Cropanzano, R., Rupp, D. E., \& Byrne, Z. S. (2003). The relationship of emotional exhaustion to work attitudes, job performance, and organizational citizenship behaviors. Journal of Applied Psychology, 88(1), 160-169.

Frost, L., \& Hoggett, P. (2008). Human agency and social suffering. Critical Social Policy, 28(4), 438-460.

Griffeth, R. W., Hom, P. W., \& Gaertner, S. (2000). A meta-analysis of antecedents and correlates of employee turnover: Update, moderator tests, and research implications for the next millennium. Journal of Management, 26(3), 463-488.

Harris, K. J., Kacmar, K. M., \& Zivnuska, S. (2007). An investigation of abusive supervision as a predictor of performance and the meaning of work as a moderator of the relationship. The Leadership Quarterly, 18(3), 252-263.

Harvey, P., Stoner, J., Hochwarter, W., \& Kacmar, C. (2007). Coping with abusive supervision: The neutralizing effects of ingratiation and positive affect on negative employee outcomes. The Leadership Quarterly, 18, 264-280.

Hui, C., \& Lee, C. (2000). Moderating effects of organization-based self-esteem on organizational uncertainty: Employee response relationships. Journal of Management, 26(2), 215-232.

Johnson, R. E., \& Lord, R. G. (2010). Implicit effects of justice on self-identity. Journal of Applied Psychology, 95(4), 681695.

King, L. A., \& Patterson, C. (2000). Reconstructing life goals after the birth of a child with

Down syndrome: Finding happiness and growing. International Journal of Rehabilitation \& Health, 5(1), 17-30.

Lin, W., Wang, L., \& Chen, S. (2013). Abusive supervision and employee well-being: The moderating effect of power distance orientation. Applied Psychology, 62(2), 308-329.

Markus, H., \& Nurius, P. (1986). Possible selves. American Psychologist, 41(9), 954-969.

Martinko, M. J., Harvey, P., Brees, J. R., \& Mackey, J. (2013). A review of abusive supervision research. Journal of Organizational Behavior, 34(1), 120-137.

Mitchell, M. S., \& Ambrose, M. L. (2007). Abusive supervision and workplace deviance and the moderating effects of negative reciprocity beliefs. Journal of Applied Psychology, 92(4), 1159-1168.

Nadiri, H., \& Tanova, C. (2010). An investigation of the role of justice in turnover intentions, job satisfaction, and organizational citizenship behavior in hospitality industry. International journal of Hospitality Management, 29(1), 33-41. 
Payne, H. J. (2007). The role of organization-based self-esteem in employee dissent expression. Communication Research Reports, 24(3), 235-240.

Pierce, J. L., \& Gardner, D. G. (2004). Self-esteem within the work and organizational context: A review of the organizationbased self-esteem literature. Journal of management, 30(5), 591-622.

Pierce, J. L., Gardner, D. G., Cummings, L. L., \& Dunham, R. B. (1989). Organization-based self-esteem: Construct definition, measurement, and validation. Academy of Management Journal, 32(3), 622-648.

Pierce, J. L., Gardner, D. G., Dunham, R. B., \& Cummings, L. L. (1993). Moderation by organization-based self-esteem of role condition-employee response relationships. Academy of Management Journal, 36(2), 271-288.

Tepper, B. J. (2000). Consequences of abusive supervision. Academy of Management Journal, 43(2), 178-190.

Thau, S., Bennett, R. J., Mitchell, M. S., \& Marrs, M. B. (2009). How management style moderates the relationship between abusive supervision and workplace deviance: An uncertainty management theory perspective. Organizational Behavior \& Human Decision Processes, 108(1), 79-92.

Turner, J. C., \& Onorato, R. S. (1999). Social identity, personality, and the self-concept: A self-categorization perspective. In T. R. Tyler, R. M. Kramer, \& O. P. John (Eds.), The Psychology of the Social Self (11-46). Mahwah, NJ: Erlbaum.

Uçar, T., \& Uzun, Ö. (2008). Examination of effect on body image, self-esteem and marital adjustment of mastectomy in women with breast cancer (Meme kanserli kadınlarda mastektominin beden algısı, benlik saygısı ve es uyumu üzerine etkisinin incelenmesi). The Journal of Breast Health, 4(3), 162-168.

Vogel, R. M., \& Mitchell, M. S. (in press). The motivational effects of diminished self-esteem for employees who experience abusive supervision. Journal of Management.

Yu, K., Lin, W., Wang, L., Ma, J., Wei, W., Wang, H., \& Shi, J. (2014). The role of affective commitment and future work self-salience in the abusive supervision-job performance relationship. Journal of Occupational \& Organizational Psychology, 89(1), 28-45. 